\title{
"Quid autem vides festucam in oculo fratris tui et trabem in oculo tuo non vide" on the hyperthyroidism-induced mortality and antithyroid drug-induced side effects in the era of radioiodine fake news
}

\author{
Luca Giovanella ${ }^{1,2,3}$. Frederik A. Verburg ${ }^{1,4}$ • Petra Petranović Ovčariček ${ }^{1,5} \cdot$ loannis lakovou ${ }^{1,6}$ • Jasna Mihailovic ${ }^{1,7,8}$. \\ Alexis Vrachimis $^{1,9}$. Slimane Zerdoud ${ }^{1,10}$ - Martha Hoffmann ${ }^{1,11}$ • Markus Luster ${ }^{1,4}$
}

Published online: 10 March 2020

(C) Springer-Verlag GmbH Germany, part of Springer Nature 2020

Radioactive iodine (RAI) is widely used to treat patients with Graves' disease, as either initial therapy or following failure of thionamides, and thyroid nodular autonomy. The recent publication of a study from Kitahara and colleagues [1], indicating a slightly higher relative risk of breast cancer in hyperthyroid patients receiving RAI therapy, started a large debate that is mainly focused on methodological limitations [2-4]. Quite surprisingly, two of Kitahara's study co-authors showed, using data from the same cohort, that the standardized mortality ratio (SMR) for breast cancer is higher for patients treated with antithyroid drugs compared with patients treated with RAI [5]. Finally, Gronich and colleagues recently investigated the association of RAI treatment with the development of cancers (both all and site-specific) in 16,637 hyperthyroid patients treated with RAI or thionamides [6]. Overall, 825 newly diagnosed cancers were detected during follow-up, and, as the main result, RAI was not associated with a higher risk of any cancer, breast cancer, colorectal cancer, prostate cancer, stomach cancer, or urinary tract cancer, compared with thionamides. Additionally, RAI therapy was associated with

This article is part of the Topical Collection on Endocrinology

Luca Giovanella

luca.giovanella@eoc.ch; https://www.eoc.ch

EANM Thyroid Committee, Vienna, Austria

2 Clinic for Nuclear Medicine and Thyroid Centre, Imaging Institute of Southern Switzerland, Ospedale San Giovanni, Via Ospedale 6, 6500 Bellinzona, Switzerland

3 Clinic for Nuclear Medicine, Zurich University Hospital, Zurich, Switzerland

4 Department of Nuclear Medicine, University Hospital Marburg, Marburg, Germany

5 Department of Oncology and Nuclear Medicine, University Hospital Center "Sestre milosrdnice", Zagreb, Croatia a lower risk of thyroid cancer, while treatment with thionamides was associated with a higher overall mortality rate than treatment with RAI. Surprisingly, while Kitahara's saga was raging, relevant concerns raised about the association of hyperthyroidism with cardiovascular mortality and risk of dementia went almost unnoticed as well as the inclusion of acute pancreatitis as a serious side effect of methimazole.

\section{Hyperthyroidism and its insufficient treatment increase cardiovascular mortality and risk of dementia}

Hyperthyroidism has been reported to cause excess all-cause and circulatory mortalities, and cardiovascular disease remains the most prevalent cause of death in hyperthyroidism [7]. Recently, a case-control study nested within a populationbased cohort study was designed to clarify the association between hyperthyroidism and cardiovascular events in treated and untreated hyperthyroid individuals. Importantly, the

6 Department of Nuclear Medicine, Aristotle University, Thessaloniki, Greece

7 Department of Radiology, Faculty of Medicine, University of Novi Sad, Novi Sad, Serbia

8 Department of Nuclear Medicine, Oncology Institute of Vojvodina, Sremska Kamenica, Serbia

9 Department of Nuclear Medicine, German Oncology Center, University Hospital of the European University, Limassol, Cyprus

10 Department of Nuclear Medicine, Nuclear Oncology and Thyroidological Oncology, University Cancer Institute-Oncopole, Toulouse, France

11 Department of Nuclear Medicine, Radiology Center, Vienna, Austria 
impact of cumulative periods of hyperthyroidism (i.e., suppressed TSH) as a proxy for undertreatment on cardiovascular events was also accounted for [8]. A total of 20,651 individuals experienced a cardiovascular event, and compared with euthyroid individuals, increased cardiovascular risk was found in untreated but treated hyperthyroid patients. However, the odds ratios for cardiovascular events were 1.09 ((CI 1.05-1.14), $p<0.001$ ) and 1.10 ((CI 1.05-1.15), $p<0.001)$ per 6 months of decreased TSH in treated and untreated hyperthyroid patients, respectively. Then, the increased cardiovascular risk is driven not only by lack of treatment but also by insufficient therapy. This is well in line with previous studies supporting supported timely treatment with radioiodine activities sufficient to induce overt hypothyroidism in order to reduce cardiovascular risk [9]. In addition to cardiovascular risks, both overt and subclinical hyperthyroidisms are known to lead to cognitive impairment $[10,11]$. Accordingly, the analysis of two Danish's cohorts of 56,128 and 2688 patients with hyperthyroidism found that 2689 and 190 patients were subsequently diagnosed with dementia and confirmed significantly increased risk of dementia, whether Alzheimer's or vascular, in both Graves' disease and toxic nodular goiter compared with euthyroid populations. Again, for each 6 months of decreased TSH, the risk of all-cause dementia further increased independently by treatment [12].

\section{The methimazole-induced acute pancreatitis: one more serious side effect of antithyroid drugs}

\footnotetext{
About 1 year ago, the European Medicines Agency (EMA) warned for the methimazole-induced acute pancreatitis and the product labeling was changed to include acute pancreatitis as a serious side effect (https://www.ema.europa.eu/ en/medicines/human/referrals/metamizole-containingmedicinal-products). In particular, basing on a registrybased study nested in cohorts of all ever users of methimazole or propylthiouracil on 119,697 patients, ongoing use of methimazole was associated with a $56 \%$ increase in the risk of being admitted to hospital due to acute pancreatitis [13]. Propylthiouracil (PTU) was not associated with an increased risk, but changing the recommended use of methimazole over propylthiouracil as the primary drug for treatment of hyperthyroidism is critical as, since 2010, a US Food and Drug Administration (FDA) boxed warning emphasizes the risk for severe liver injury and acute liver failure, some of which have been fatal, induced by PTU (https://www.fda.gov/drugs/postmarket-drugsafety-information-patients-and-providers/fda-drug-safetycommunication-new-boxed-warning-severe-liver-injurypropylthiouracil).
}

\section{Conclusions}

The newly released National Institute for Health and Care Excellence (NICE) guideline (NG145) on "Thyroid Diseases: assessment and management" (https://www.nice. org.uk/guidance/ng145) supports radioiodine as first-line treatment for most people with hyperthyroidism secondary to Graves' disease. Such strong recommendation was based on "clinical and economic evidence, that radioactive iodine produced better long-term outcomes and was more costeffective than antithyroid drugs." Considering that long-term suppressed TSH levels and relapsing hyperthyroidism (with attached risks summarized above) are typically observed in patients treated with ATD (with attached risk of serious side effects) "it would be unfortunate if patients were deprived of the option of rapid, effective control of their hyperthyroidism with radioiodine, due to concerns of cancer risk" as recently stated by the Executive Committees of the Society for Endocrinology and the British Thyroid Association [14].

In conclusion, information to our patients should be based on proper consideration of the available evidences [15] that, in the absence of convincing data supporting a higher risk of cancer-related mortality in patients treated with radioiodine, suggest superiority of RAI over antithyroid drugs in terms of both safety, success rate, and cost effectiveness.

\section{Compliance with ethical standards}

Conflict of interest LG is a member of Roche Diagnostics advisory board and has received research grants and speaker honoraria from Roche Diagnostics, IBSA, and Sanofi-Genzyme. FAV has received research grants from Sanofi-Genzyme and speaker honoraria from SanofiGenzyme, Diasorin, and Jubilant Draximage. The other authors declare no conflict of interests.

Ethical approval This article does not contain any studies with human participants or animals performed by any of the authors.

\section{References}

1. Kitahara CM, Berrington de Gonzalez A, Bouville A, et al. Association of radioactive iodine treatment with cancer mortality in patients with hyperthyroidism. JAMA Intern Med 2019; 179: 1034-1042.

2. Greenspan BS, Siegel JA, Hassan A, Silberstein EB. There is no associaton of radioactive iodine treatment with cancer mortality in patients with hyperthyroidism. J Nucl Med. 2019;60:1500-1.

3. Hindie E, Ain KB, Zerdoud S, Avram A. Association of radioactive iodine treatment of hyperthyroidism with cancer mortality: an unjustified warning? J Clin Endocrinol Metab. 2019. https://doi.org/ 10.1210/clinem/dgz305.

4. Verburg FA, Hoffmann M, Iakovou I, Konijnenberg MW, Mihailovic J, Gabina PM, et al. Errare humanum est, sed in errare perseverare diabolicum: methodological errors in the assessment of the relationship between I-131 therapy and possible increases in the 
incidence of malignancies. Eur J Nucl Med Mol Imaging. 2020;47: 519-22.

5. Tulchinsky M, Brill AB. Spotlight on the association of radioactive iodine treatment with cancer mortality in patients with hyperthyroidism is keeping the highest risk from antithyroid drugs in the blind spot. Clin Nucl Med. 2019;44:789-91.

6. Gronich N, Lavi I, Rennert G, Saliba W. Cancer risk after radioactive iodine treatment for hyperthyroidism: a cohort study. Thyroid. 2020;30:243-50.

7. Lillevang-Johansen M, Abrahamsen B, Jørgensen HL, Brix TH, Hegedüs L. Duration of hyperthyroidism and lack of sufficient treatment are associated with increased cardiovascular risk. Thyroid. 2019;29:332-40.

8. Lillevang-Johansen M, Abrahamsen B, Jørgensen HL, Brix TH, Hegedüs L. Excess mortality in treated and untreated hyperthyroidism is related to cumulative periods of low serum TSH. J Clin Endocrinol Metab. 2017;102:2301-9.

9. Franklyn JA, Sheppard MC, Maisonneuve P. Thyroid function and mortality in patients treated for hyperthyroidism. JAMA. 2005;294: 71-80.

10. Chaker L, Wolters FJ, Bos D, Korevaar TIM, Hofman A, van der Lugt A, et al. Thyroid function and the risk of dementia: the Rotterdam study. Neurology. 2016;87:1688-95.
11. Rieben C, Segna D, da Costa BR, Collet TH, Chaker L, Aubert CE, et al. Subclinical thyroid dysfunction and the risk of cognitive decline: a meta-analysis of prospective cohort studies. J Clin Endocrinol Metab. 2016;101:4945-54.

12. Folkestad L, Brandt F, Lillevang-Johansen M, Brix TH, Hegedus L. Graves' disease and toxic nodular goiter, aggravated by duration of hyperthyroidism, are associated with Alzheimer's and vascular dementia. A register-based long-term follow-up of two large cohorts. Thyroid 2020. doi: https://doi.org/10.1089/thy.2019.0672.

13. Brix TH, Lund LC, Henriksen DP, Folkestad L, Bonnema SJ, Hallas J, et al. Hegedüs L. Methimazole and risk of acute pancreatitis. Lancet Diabetes Endocrinol 2020; 8:187-189.

14. Taylor PN, Okosieme EO, Chatterjee K, Boelaert K. Joint statement from the Society for Endocrinology and the British Thyroid Association regarding "association of radioactive iodine treatment with cancer mortality in patients with hyperthyroidism". Clin Endocrinol. 2020;92:266-7.

15. Giovanella L, Verburg FA. Use of anti-thyroid drugs in patients with hyperthyroidism: a case for shared decision-making. Eur J Nucl Med Mol Imaging. 2019;46:2408-9.

Publisher's note Springer Nature remains neutral with regard to jurisdictional claims in published maps and institutional affiliations. 